Original Research Article

\title{
Clinical profile and outcomes of snake bite poisoning in a tertiary care centre in South Tamilnadu
}

\author{
Meenakshi B. ${ }^{1}$, Shantaraman K. ${ }^{2}$, Indhumathi M. ${ }^{1}$, Arumugapandian S. Mohan ${ }^{3}$
}

\author{
${ }^{1}$ Department of Pharmacology, \\ ${ }^{2}$ Department of Pathology, \\ ${ }^{3}$ Department of General \\ Medicine, Tirunelveli Medical \\ College, Tirunelveli, Tamilnadu, \\ India
}

Received: 10 December 2016

Accepted: 31 December 2016

\section{*Correspondence to: \\ Dr. Meenakshi B., \\ Email: \\ meenakshi_b@tvmc.ac.in}

Copyright: (C) the author(s), publisher and licensee Medip Academy. This is an openaccess article distributed under the terms of the Creative Commons Attribution NonCommercial License, which permits unrestricted noncommercial use, distribution, and reproduction in any medium, provided the original work is properly cited.

\begin{abstract}
Background: Snake-bites are well-known common medical emergencies in many parts of the world. In India 46,000 people are dying every year from snakebites. However, the true scale of mortality and morbidity from snake-bite remains uncertain. This study analyses the clinical profile and outcomes of the snake bite poisoning in patients admitted to this centre.

Methods: This cross sectional study analyses the data of 150patients admitted to the Intensive Medical Care Unit of Tirunelveli Medical College Hospital with the history of snake bite between April and September of 2015 as available in their case records.

Results: In this study, $42.7 \%$ of the patients were in the age group of 18 to 40 years and $64 \%$ were males with rural: urban ratio of 2.3: 1 . About $82.7 \%$ of bites were haematotoxic, $10.7 \%$ neurotoxic and the remaining nontoxic bites. About $54 \%$ patients recovered completely, $44 \%$ had some form of morbidity at discharge and mortality was $2 \%$. Out of 136 patients who were treated with Anti-snake venom (ASV), 9.6\% developed ADR. The common ADR was itching and hypotension followed by rigor, breathlessness and edema of lips and eyes.

Conclusions: This study highlights the need for early treatment intervention post bite. Imparting health education about early pre-hospital management and transfer to the hospital will help in the prevention of deaths due to snakebite. Identification of the type of snake is essential to decide on the type of toxicity and method of treatment to be instituted.
\end{abstract}

Keywords: Antisnake venom, Advere drug reactions, Haemotoxic, Neurotoxic, Snake bite

\section{INTRODUCTION}

Snake-bites are well-known common medical emergencies in many parts of the world, especially in the rural areas. The incidence of snake-bite mortality is particularly high in South-East Asia. Agricultural workers are the most affected. ${ }^{1}$ About 2500 species of snakes exist in the world. India has over 250 species and subspecies, out of which 50 are venomous. ${ }^{2}$ Mainly 4 venomous land snakes pose public health problem in India. They are elapidae, including cobra (Naja naja) and krait (Bungarus caeruleus) and viperidae Russell's viper (Daboia russelii) and saw scaled viper (Echis carinatus). ${ }^{3}$ World mortality from snake bite is estimated as 50,000 to 1, 00,000 annually (McNamee 2001). ${ }^{4}$ In India 46,000 people are dying every year from snakebites. More than
2.5 lakh cases of snake bites are reported every year. ${ }^{5}$ Largest number of deaths reported in India is from Uttar Pradesh (UP), Andhrapradesh and Bihar. ${ }^{6}$ However, the true scale of mortality and acute and chronic morbidity from snake-bite remains uncertain. ${ }^{7}$ Death occurs in these patients due to delay in reaching a hospital within the golden hour, lack of availability of specific treatment, or toxicity to anti-venom. ${ }^{5}$ It has been recommended that snake-bite should be a notifiable disease in many countries in the South East Asian region. ${ }^{8}$ This hospital is a tertiary care centre, where 250-300patients with snake bite poisoning are admitted annually mostly referred from primary health centres and other regional hospitals. This study analyses the clinical profile and outcomes of the snake bite poisoning in patients admitted to this centre. 


\section{Objectives}

This study aims to describe and analyse various clinical features due to snake bite, the various outcomes and to document the adverse drug reaction profile of Anti-snake venom treatment in such victims admitted in Tirunelveli Medical College Hospital for a period of 6 months between April and September of 2015.

\section{METHODS}

The study commenced after due approval of the Institutional Ethical Committee. This cross sectional study analyses the data of 150patients admitted to the
Intensive Medical Care Unit of Tirunelveli Medical College Hospital with the history of snake bite between April and September of 2015 as available in their case records in the Medical Records Department.

The data were recorded in structured proforma including details of demography, type of snake involved in the bite, condition of the patient at admission, treatment given, total requirement of ASV and any adverse event recorded after ASV and outcome of the patients were collected. The data were analysed statistically.

\section{RESULTS}

Table 1: Demographic profile and outcome of snake bite victims, types and toxicity of the snakes and adverse drug reaction profile of anti snake venom.

\begin{tabular}{|c|c|c|c|c|}
\hline No & & & Number of patients $n=\mathbf{1 5 0}$ & $\%$ of Patients \\
\hline \multirow[t]{5}{*}{1} & Age & $0-12$ & 0 & 0 \\
\hline & & $12-18$ & 15 & 10 \\
\hline & & $18-40$ & 64 & 42.7 \\
\hline & & $41-60$ & 51 & 34 \\
\hline & & $>60$ & 20 & 13.3 \\
\hline \multirow[t]{2}{*}{2} & Gender & Male & 96 & 64 \\
\hline & & Female & 54 & 36 \\
\hline \multirow[t]{2}{*}{3} & Domicile & Rural & 104 & 69.3 \\
\hline & & Urban & 46 & 30.7 \\
\hline \multirow[t]{4}{*}{4} & Site of snake bite & UL & 29 & 19.3 \\
\hline & & LL & 120 & 80 \\
\hline & & Trunk & 0 & 0 \\
\hline & & Head and neck & 1 & 0.7 \\
\hline \multirow[t]{4}{*}{5} & First Aid received & Home Based & 78 & 52 \\
\hline & & Primary Health Centre & 10 & 6.7 \\
\hline & & Secondary Care Hospital & 55 & 36.7 \\
\hline & & Private Hospital & 7 & 4.7 \\
\hline \multirow[t]{5}{*}{6} & Type of snake & Known & 28 & 18.7 \\
\hline & & Saw Scaled Viper & 20 & \\
\hline & & Russell Viper & 3 & \\
\hline & & Cobra & 5 & \\
\hline & & Unknown & 122 & 81.3 \\
\hline \multirow[t]{4}{*}{7} & Toxic symptoms & Hematotoxic & 124 & 82.7 \\
\hline & & Neurotoxic & 16 & 10.7 \\
\hline & & anaphylotoxic & 0 & 0 \\
\hline & & Others & 10 & 6.7 \\
\hline 8 & Treated with ASV & & 136 & 90.7 \\
\hline \multirow[t]{5}{*}{9} & ADR to ASV & & 13 & 9.6 \\
\hline & & Itching and hypotension & 5 & 38.5 \\
\hline & & Itching and breathlessness & 3 & 23.1 \\
\hline & & Chills and rigor & 4 & 30.8 \\
\hline & & Itching and oedema & 1 & 7.7 \\
\hline \multirow[t]{3}{*}{10} & Complications & Cellulitis & 75 & 50 \\
\hline & & Acute kidney injury & 66 & 44 \\
\hline & & DIC & 3 & 6 \\
\hline & Outcome & Recovered & 81 & 54 \\
\hline & & With morbidity & 66 & 44 \\
\hline & & Death & 3 & 2 \\
\hline
\end{tabular}


The case records of 150 patients admitted with the history of snake bite were studied. The predominant age group was 18-40 years followed by 41-60 years and $64 \%$ of them were males. About $69.3 \%$ were from rural area. In $81.3 \%$ of cases, the species of the snake was not known. Hemotoxic symptoms were present in $82.7 \%$ and neurotoxic symptoms in $10.7 \%$ of the patients. Cellulitis $(50 \%)$ was the most common complication due to snake bite followed by acute kidney injury (44\%) and disseminated intravascular coagulation (DIC in 6\%). Out of 150 patients $54 \%$ recovered completely, $2 \%$ died and the remaining had some cellulitis or kidney injury at the time of discharge. Almost $90.7 \%$ of the patients were treated with polyvalent anti snake venom for which $9.6 \%$ of the patients developed adverse drug reactions. The results are depicted in Table 1.

\section{DISCUSSION}

Snakebite is an imminently treatable condition which predominantly affects tropical countries with the highest rate of snakebite poisoning related deaths occurring in south Asia, especially the Indian subcontinent. ${ }^{9,10}$ In India, approximately 2,00,000 people are affected by snakebite poisoning, of whom 15,000 to 30,000 patients die every year. ${ }^{4}$ Tamilnadu is one of the states with a high prevalence of snake-bite related deaths with a CDR of 4.7 per 100,00 patients. $^{11}$ Indian reports on the clinical profiles, outcomes and ASV related adverse drug reactions are sparse.

In this study, $42.7 \%$ of the patients were in the age group of 18 to 40 years and $64 \%$ were males which was similar to other Indian reports. ${ }^{4,12,13}$ This could possibly be due to the social behaviour of men as the dominant earning member of the family working out-doors. Of the patients, $69.33 \%$ were domiciled in rural areas with a rural: urban ratio of 2.3: 1 similar to other studies reported. ${ }^{12,13}$ Higher incidence in rural areas can be attributed to farming as an occupation, the habit of walking barefoot and thatched unprotected households. The site of bite was predominantly in the lower limb (80\%) while one person had bite in the face.

The type of snake was identified based on interviewing the patient or bystanders and the species was identifiable only in 28 of the $150(18.7 \%)$ patients. The commonest identified species was the saw scaled viper $(71.4 \%)$ followed by cobra and Russell viper which is in variance to the report of Mohankumar et al based on data collected in the year 2012 in northern Tamilnadu, where Russell Viper and Cobra were the commonest species. ${ }^{13}$

Of the 150 patients 140 snake bites were classified as due to poisonous species of snakes of whom $82.7 \%$ were haematotoxic and $10.7 \%$ were neurotoxic. The remaining 10 patients were bitten by non-poisonous species.

Of the 150 patients admitted to this hospital, the major proportion of patients $(52 \%)$ had home based treatment initially. Of the remaining 72 patients, 10 were initially treated in primary health centres, 55 in district or taluk hospitals and 7 in private clinics.

The common reason for transfer or admission of these patients to this tertiary medical centre was prolonged clotting time not responding to treatment in $29.16 \%$ of patients.

The patients received at this medical centre were given intensive medical care as per hospital protocols. Polyvalent Anti snake venom (Serum India Inc) was administered intravenously based on the body weight of the patient. The patients were continuously monitored for haematological, renal, cardiac, respiratory and neurological parameters. Of these $4 \%$ received blood transfusion (whole blood or fresh frozen plasma).

The average duration of stay of patients was 7 days while 4 of the 150 patients needed more than 3 weeks of stay of whom 3 had neuro-toxic complications.

The presenting complaint in $94(62.7 \%)$ of these patients was local pain associated with local cellulitis. Bleeding manifestations were seen in $35(23.3 \%)$ patients namely bleeding at the site of bite in 31 patients, hemetemesis in 4 patients. These observations were similar to previous reports from this geographical region. ${ }^{13}$

Of 16 patients with neurotoxicity $93.6 \%$ had ptosis. Acute kidney injury was seen in $12.7 \%$ of the patients with haematotoxicity which developed through day 2 to day 5 of their hospitalization. Of these patients with acute kidney injury 3 patients needed haemodialysis. DIC was seen in 3 patients with haematotoxicity. Of the 150 patients, 18 patients needed surgical management like incision and drainage of bite site, fasciotomy, split skin graft or amputation. Five patients (31.2\%) with neurotoxicity were given ventilator support of whom 3 patients developed irreversible respiratory failure and died.

This study highlights the morbidity and mortality associated with snake bite. Of the 150 patients studied, 3 patients died due to respiratory arrest, while there was no mortality associated with haematotoxicity. Only $16 \%$ of patients reached the hospital within the first hour of the snake bite, while $62.66 \%$ reached between 1 and 6 hours post bite. In neurotoxic snake bites, the time lapse between the bite and initiation of anti-snake venom treatment was 5 hours on average in patients who died, while it was 2 hours in those who recovered. This underlines the need for early treatment intervention. The time lapse could be attributed to lack of awareness of complications of snake bite, habit of seeking traditional methods of treatment or lack of treatment facilities nearer to home. ${ }^{14}$

Of the 54\% patients who recovered completely 61 patients were affected by hematotoxicity. Number of 
victims who had some form of morbidity like cellulitis (6), non-healing wounds (4), amputated digits or limb (2), elevated renal parameters (66) etc. at the time of discharge was $44 \%$. Among these most of them were hemotoxic snake bite victims. Among the 150 victims in the study only $2 \%$ died and all of them were due to neuroparalysis.

Out of 136 patients who were treated with Anti-snake venom (ASV), 9.6\% developed adverse reactions. The common adverse drug reaction was itching and hypotension in 5 patients followed by rigor, breathlessness and oedema of lips and eyes.

\section{CONCLUSION}

This study concludes the following:

1. This study highlights the need for early treatment intervention post bite. The rate of recovery was better when the patients were administered anti snake venom within 1 hour of the bite.

2. The time lapse could be attributed to lack of awareness of complications of snake bite, habit of seeking traditional methods of treatment or lack of treatment facilities nearer to home.

3. Imparting health education about early pre-hospital management and need for early transfer to the hospital will help in the prevention of avoidable deaths due to snakebite.

4. Identification of the type of snake is essential to decide on the type of toxicity and method of treatment to be instituted.

Funding: No funding sources Conflict of interest: None declared

Ethical approval: The study was approved by the Institutional Ethics Committee

\section{REFERENCES}

1. David A Warrell .WHO Guidelines for management of snake-bites. $2^{\text {nd }}$ edition; 2010.

2. Chaudhari TS, Patil TB, Paithankar MM, Gulhane RV, Patil MB. Predictors of mortality in patients of poisonous snake bite: Experience from a tertiary care hospital in Central India. Int $\mathbf{J}$ Critical Illness and Injury Science. 2014;4(2):101-7.

3. Kasturiratne A, Wickremasinghe AR, de Silva N, Gunawardena NK, Pathmeswaran A, Premaratna R, et al. The Global Burden of Snakebite: A Literature Analysis and Modeling Based on Regional Estimates of Envenoming and Deaths. PLoS Med. 2008;5(11):e218.
4. Bhalla G, Mhaskar D, Agarwal A. A Study of Clinical Profile of Snake Bite at a Tertiary Care Centre .Toxicology International. 2014;21(2):203-8.

5. Sinha K. Snake bites kill $46 \mathrm{~K}$ in India yearly- Times of India. TNN | Dec 6, 2011.

6. Mohapatra B. Snakebite Mortality in India: A Nationally Representative Mortality Survey PLoS Negl Trop Dis. 2011;5(4):e1018.

7. Halesha BR, Harshavardhan L. A Study on the Clinico-Epidemiological Profile and the Outcome of Snake Bite Victims in a Tertiary Care Centre in Southern India. Journal of Clinical and Diagnostic Research. 2013;1:122-6.

8. Gupta YK, Peshin SS. Snake Bite in India: Current Scenario of an Old Problem. J Clin Toxicol. 2014;4:182.

9. Snakebites - World Health Organization. Available at www.who.int/neglected_diseases/diseases/World_Re port_Child_Injury_Prevention.

10. Kasturiratne A. The Global Burden of Snakebite: A Literature Analysis and Modelling Based on Regional Estimates of Envenoming and Deaths. 2008. Available at http://dx.doi.org/10.1371/journal.pmed.0050218.

11. Vaiyapuri S. Snakebite and Its Socio-Economic Impact on the Rural Population of Tamil Nadu, India. https://www.ncbi.nlm.nih.gov:NCBI:Literature: PubMed Central (PMC) Published: November 21, 2013. Available at http://dx.doi.org/10.1371/journal.pone.0080090

12. Saravu K, Somavarapu V. Clinical profile, speciesspecific severity grading, and outcome determinants of snake envenomation: An Indian tertiary care hospital-based prospective study. Indian Journal of Critical Care Medicine. 2012;16;4;187-92.

13. Mohankumar P, Sivagurunathan C. Study on the clinico-epidemiological profile and the outcome of snake bite victims in a rural health centre in Kancheepuram district, Tamilnadu. International Journal of Pharma and Bio Sciences. 2015;6(2);54450 .

14. Ahmed SM, Ahmed M, Nadeem A, Mahajan J, Choudhary A, Pal J. Emergency treatment of a snake bite: Pearls from literature. J Emerg Trauma Shock. 2008;1(2):97-105.

Cite this article as: Meenakshi $\mathrm{B}$, Shantaraman $\mathrm{K}$, Indhumathi M, Arumugapandian SM. Clinical profile and outcomes of snake bite poisoning in a tertiary care centre in South Tamilnadu. Int J Basic Clin Pharmacol 2017;6:418-21. 